Thorax, 1978, 33, 72-75

\title{
Ductus arteriosus sling: Report of a newly recognised anomaly and its surgical correction
}

\author{
J. P. BINET, J. F. CONSO, J. LOSAY, Ph. NARCY, E. J. RAYNAUD, Fr. BEAUFILS, \\ C. DOR, AND J. BRUNIAUX
}

From the Centre Chirurgical Marie-Lannelongue, 133 avenue de la Résistance, 92350 le Plessis-Robinson, France

Binet, J. P., Conso, J. F., Losay, J., Narcy, Ph., Raynaud, E. J., Beaufils, Fr., Dor, C., and Bruniaux, J. (1978). Thorax, 33, 72-75. Ductus arteriosus sling. Report of a newly recognised anomaly and its surgical correction. Surgical exploration of a 7-week-old infant with a diagnosis of 'pulmonary artery sling' (left pulmonary artery arising from the right) revealed the true nature of the abnormality to be persistence of the ductus arteriosus which connected the right pulmonary artery to the aortic isthmus. This malformation has not been described previously. It has the same symptomatology as 'pulmonary artery sling' and it may be treated by surgical ligation and division. We suggest the term 'ductus arteriosus sling' to describe this rare congenital anomaly.

Compression of the posterior aspect of the trachea by a left pulmonary artery arising from the right and passing between the trachea and oesophagus is now well documented (Binet and Langlois, 1977). Seventyfive cases, 39 of which underwent surgery with 21 deaths, have been summarised in a recent review of the literature (Grover et al., 1975). We can add a personal series of five cases with two deaths due to malacia which affected the trachea more than the bronchi (Langlois et al., 1970).

The following case report concerns similar airway compression by a persistent ductus arteriosus which connected the right main pulmonary artery to the isthmic portion of the thoracic aorta, having passed between the trachea and the oesophagus.

We have been unable to find any published report of this malformation and suggest the term 'ductus arteriosus sling'.

\section{Case report}

A 7-week-old infant weighing $4.5 \mathrm{~kg}$ was admitted to the Marie Lannelongue Surgical Clinic. An endotracheal tube was in place. She had been referred from the intensive care unit of the Bretonneau Hospital (Professor Mathieu and Professor Beaufils). The endotracheal tube had been inserted after an episode of asphyxia following a long period of dyspnoea, intercostal retraction, and wheezing during feeding. The chest radiograph showed no abnormalities in the lungs or mediastinum. An oesophagogram and bronchoscopy revealed an obstructing, pulsatile mass at the level of the carina. An operation was performed on 14 October 1976 with the intention of dividing and re-implanting the anomalous pulmonary artery. Median sternotomy was used. Cannulae were inserted into the ascending aorta for systemic perfusion and the right atrium for venous return to the heart-lung machine. The body temperature was lowered to $20^{\circ} \mathrm{C}$ (oesophageal). Circulatory arrest was maintained for 39 minutes and the aorta was occluded for 43 minutes.

The findings at operation were surprising (Fig. 1). On dissecting the superior border of the right main pulmonary artery a vessel having the features of an anomalous left main pulmonary artery was encountered. However, there was also a small but apparently normal left main pulmonary artery running directly to the hilum of that lung. It was thought that there were two left pulmonary arteries at this $\frac{D}{0}$ stage of the dissection. The abnormal vessel was divided from the right main pulmonary artery and $N$ was traced between the trachea and the oesophagus to its termination, not at the lung hilum but into the $\mathrm{N}$ isthmic portion of the thoracic aorta (Fig. 2). The $\omega$ vessel was approximately $4 \mathrm{~mm}$ in diameter and had a broad junction with the aorta. This junction was $\stackrel{\varrho}{\subset}$ ligated. After rewarming of the patient perfusion $\mathbb{D}$ pressures were normal in all of the heart chambers ?and in both great arteries. The retro-oesophageal $\frac{0}{0}$ right subclavian artery was left in its abnormal posi- $\frac{\vec{D}}{\mathbb{D}}$ tion as it was not readily accessible through the $\stackrel{\odot}{\mathbb{P}}$ sternotomy. The postoperative course was not with- $\stackrel{\AA}{\varrho}$ out difficulties but no major complications occurred. Assisted ventilation through the endotracheal tube 


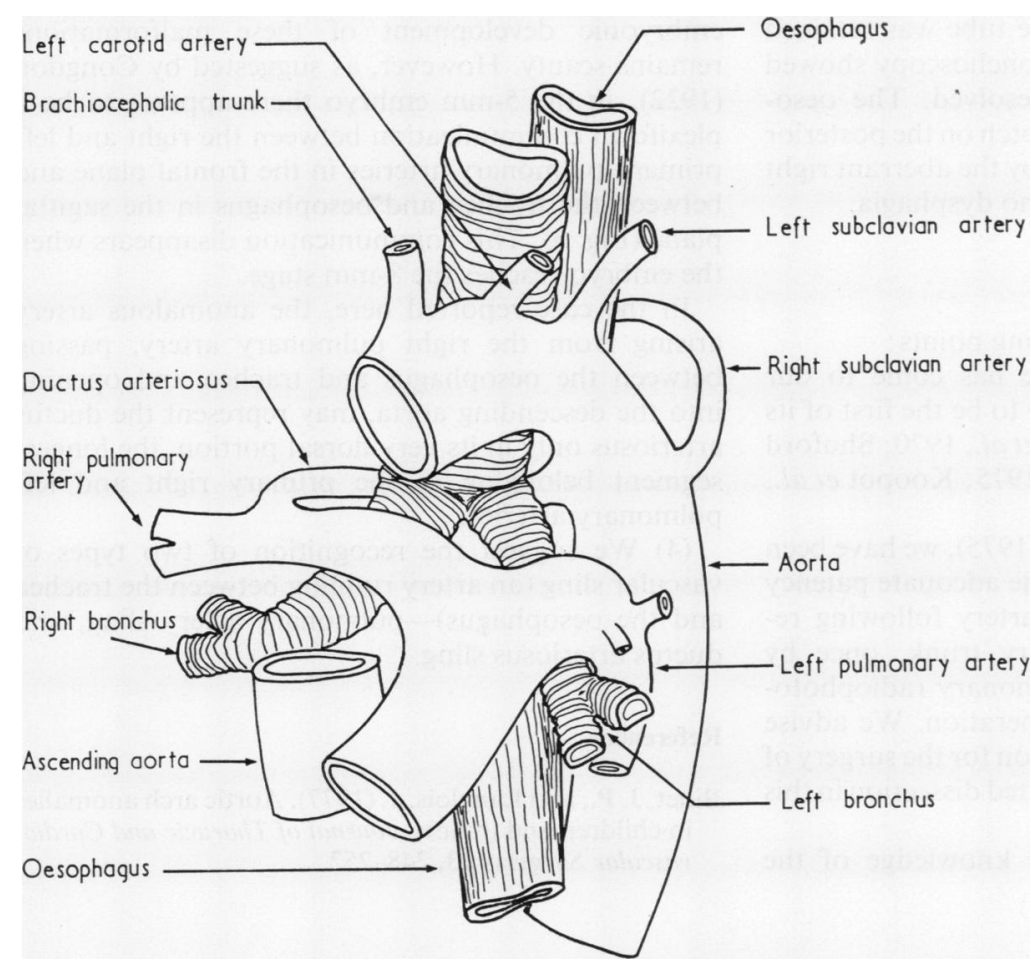

Fig. 1 Frontal view of the great vessels (artist's drawing). The abnormal ductus is seen running behind the trachea while the left pulmonary artery goes directly to the hilum of the left lung.

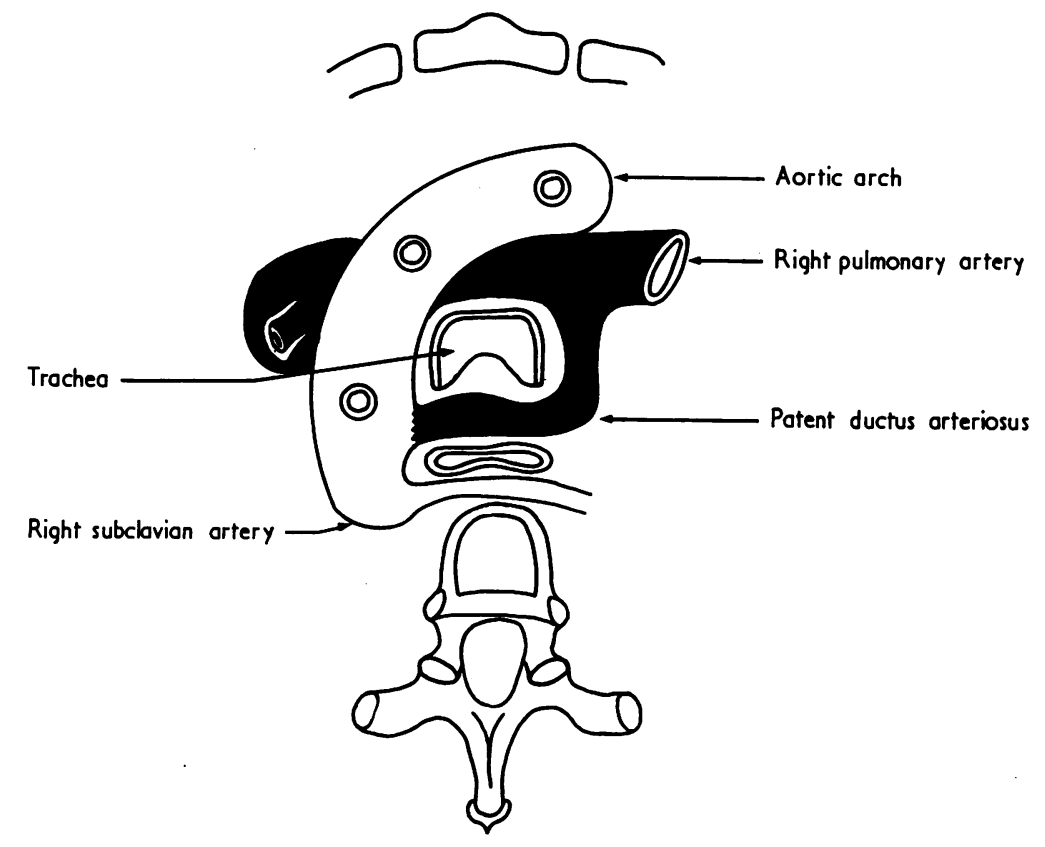

Fig. 2 Superior view of the mediastinum. The ductus arteriosus is seen running between the trachea and the oesophagus and ending in the isthmic portion of the thoracic aorta. 
was given for seven days, but the tube was retained for one month, at which time bronchoscopy showed that airway compression had resolved. The oesophagogram showed a persistent notch on the posterior aspect of the oesophagus caused by the aberrant right subclavian artery, but there was no dysphagia.

\section{Discussion}

We wish to emphasise the following points:

(1) No similar published case has come to our attention and we believe this case to be the first of its nature to be described (Langlois et al., 1970; Shuford and Sybers, 1974; Grover et al., 1975; Koopot et al., 1975).

(2) As suggested by Sade et al. (1975), we have been able to verify on two occasions the adequate patency of an aberrant left pulmonary artery following reimplantation into the pulmonary trunk, once by angiography and once by a pulmonary radiophotoscan, one and two years after operation. We advise the use of extracorporeal circulation for the surgery of these conditions. It greatly facilitated dissection in this case.

(3) Despite recent work, our knowledge of the

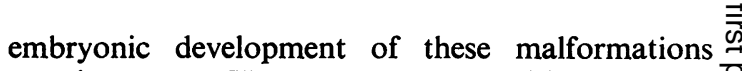
remains scanty. However, as suggested by Congdon (1922), in the 5-mm embryo there appears to be a plexiform communication between the right and left $\frac{\text { p }}{\vec{D}}$ primary pulmonary arteries in the frontal plane and $\stackrel{\mathbb{}}{\varrho}$ between the trachea and oesophagus in the sagittal \& plane (Fig. 3). This communication disappears when $\vec{\circ}$ the embryo reaches the 8-mm stage.

In the case reported here, the anomalous artery $\vec{\omega}$ arising from the right pulmonary artery, passing between the oesophagus and trachea and opening $\vec{x}$ into the descending aorta, may represent the ductus $\underset{\omega}{\omega}$ arteriosus only in its very dorsal portion, the longest segment belonging to the primary right and left $\mathrm{N}$ pulmonary arteries.

(4) We suggest the recognition of two types of vascular sling (an artery running between the trachea and the oesophagus)-pulmonary artery sling, and ductus arteriosus sling.

\section{References}

Binet, J. P., and Langlois, J. (1977). Aortic arch anomalies in children and infants. Journal of Thoracic and Cardiovascular Surgery, 73, 248-252.

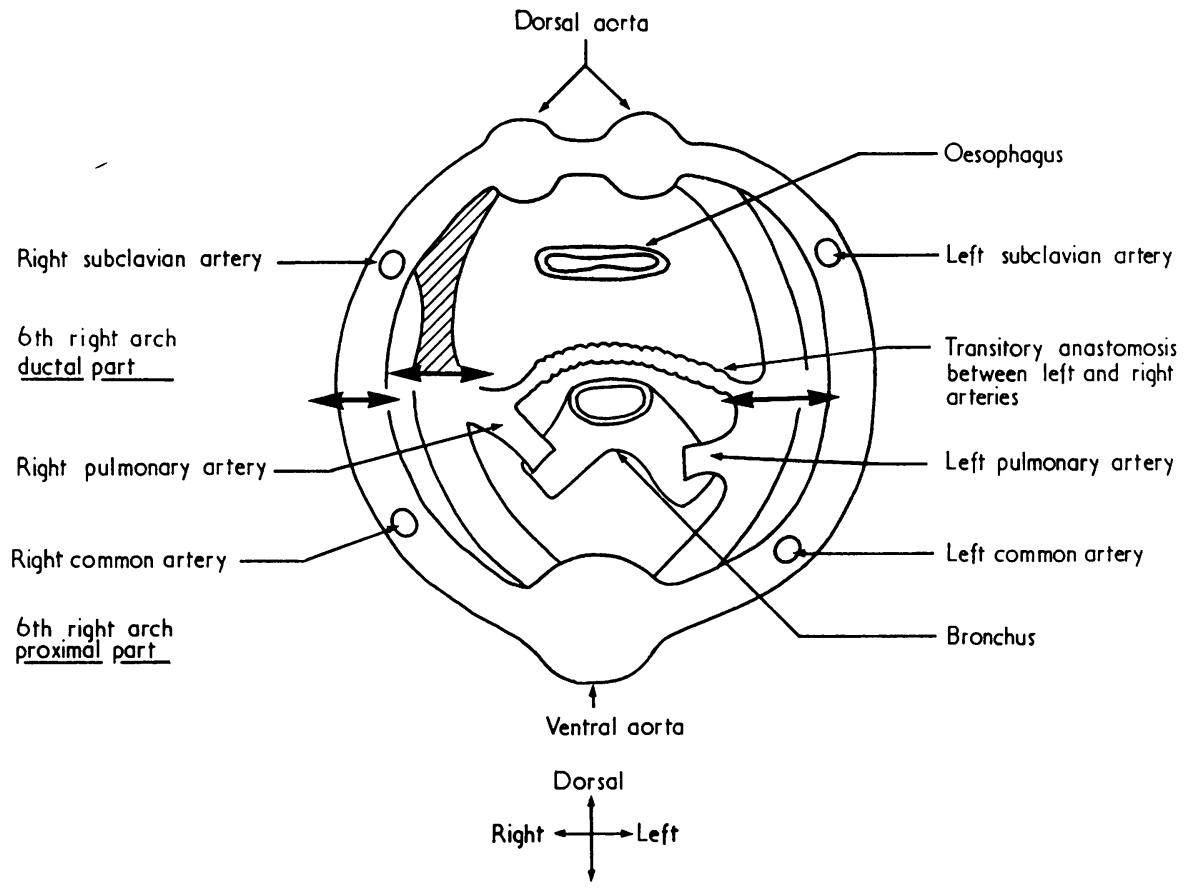

Fig. 3 Possible embryology of the anomaly. Transverse section of 8-mm stage embryo. Transitory plexiform communication is between right and left pulmonary artery. Arrows show the normal points of involution of the aortic arch. 
Congdon, E. D. (1922). Transformation of the aortic arch system during the development of the human embryo. Contributions to Embryology, 14, 47-110.

Grover, F. L., Norton, J. B., Webb, G. E., and Trinkle, J. K. (1975). Pulmonary sling: case report and collective review. Journal of Thoracic and Cardiovascular Surgery, 69, 295-300.

Koopot, R., Nikaidoh, H., and Idriss, F. S. (1975). Surgical management of anomalous left pulmonary artery causing tracheobronchial obstruction. Pulmonary artery sling. Journal of Thoracic and Cardiovascular Surgery, 69, 240-245.

Langlois, J., Germain, M., Gabilan, J. C., Pottemain, M., Belloy, A., Conso, J. F., Cloup, M., Fortier-
Beaulieu, M., Watchi, M., and Binet, J. P. (1970). L'artère pulmonaire gauche aberrante. Annales de Chirurgie Thoracique et Cardio-vasculaire, 9, 311-324.

Sade, R. M., Rosenthal, A., Fellows, K., and Castaneda, A. R. (1975). Pulmonary artery sling. Journal of Thoracic and Cardiovascular Surgery, 69, 333-346.

Shuford, W. H., and Sybers, R. G. (1974). The Aortic Arch and its Malformations. Charles C. Thomas, Springfield, Illinois.

Requests for reprints to: Professor J. P. Binet, Centre Chirurgical Marie-Lannelongue, 133 avenue de la Résistance, 92350 le Plessis-Robinson, France. 